\title{
Reinforcement of polycaprolactone/chitosan with nanoclay and controlled-release of curcumin for wound dressing
}

\author{
Yanping Huang, ${ }^{\dagger}$ Nianhua Dan, ${ }^{*}+$ Weihua Dan, $*+$ Weifeng Zhao $\S$ \\ ${ }^{\dagger}$ College of Biomass Science and Engineering, Key Laboratory for Leather Chemistry and \\ Engineering of the Education Ministry, \\ $\$$ Research Center of Biomedical Engineering, and § College of Polymer Science and \\ Engineering, State Key Laboratory of Polymer 6 Materials Engineering, Sichuan University, \\ Chengdu 610065, China \\ * Corresponding author, E-mail: danweihua_scu@126.com (Weihua Dan); \\ dannianhua@,scu.edu.cn (Nianhua Dan). Tel.: +86 28 85408988: Fax: +86 28 85408988;
}

The light transmittance of the films was measured. Each film was cut into a piece $(1 \mathrm{~cm} \times 4.5 \mathrm{~cm})$ and directly mounted between magnetic holders of the spectrophotometer, and the percent transmittance was measured using a UV-vis spectrophotometer (PerseeTU-1810 UV/Vis, Beijing, China). Transparency of the films was tested by measuring percent transmittance at $200 \mathrm{~nm}\left(\mathrm{~T}_{200}\right)$ and $660 \mathrm{~nm}\left(\mathrm{~T}_{660}\right)^{1}$. The obtained results were listed in Table S1.

It could be seen from Table $\mathbf{S} 1$ that $\mathrm{T}_{600}$ of pure $\mathrm{PCl}$ films was about $0.7 \pm 0.1 \%$, implying they were lighttight. The addition of Cur, CS or clay barely changed the transmittance. The $\mathrm{T}_{200}$ of the neat $\mathrm{PCl}$ film was $99.2 \pm 0.1 \%$. Analogously, the Cur, CS and Clay did not affect the UV light barrier properties. In summary, all the films were 
lighttight and had no UV light barrier properties. In addition, the addition of CS, Cur or clay did not affect the light transmittance.

Table S1. Light transmittance of PCl and curcumin-loading composite films.

\begin{tabular}{ccc}
\hline Film & $\mathrm{T}_{660}(\%)$ & $\mathrm{T}_{200}(\%)$ \\
\hline $\mathrm{PCl}$ & $0.7 \pm 0.1$ & $99.2 \pm 0.1$ \\
$\mathrm{PCl} / \mathrm{Cur}$ & $0.7 \pm 0.1$ & $99.1 \pm 0.1$ \\
$\mathrm{PCl} / \mathrm{CS} / \mathrm{Cur}$ & $0.7 \pm 0.1$ & $99.0 \pm 0.1$ \\
$\mathrm{PCl} / \mathrm{CS} /$ Cur/Clay-1 & $0.7 \pm 0.1$ & $99.1 \pm 0.1$ \\
$\mathrm{PCl} / \mathrm{CS} /$ Cur/ Clay-2 & $0.7 \pm 0.1$ & $99.3 \pm 0$ \\
$\mathrm{PCl} / \mathrm{CS} /$ Cur/ Clay-3 & $0.7 \pm 0.1$ & $99.2 \pm 0.1$ \\
$\mathrm{PCl} / \mathrm{CS} /$ Cur/ Clay-4 & $0.7 \pm 0.1$ & $99.1 \pm 0.1$ \\
\hline
\end{tabular}

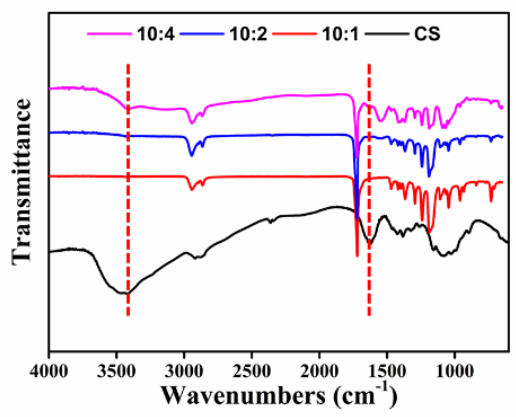

Figure S1. The FTIR spectra of CS, PCI/CS/Cur (PCl:CS=10:1), PCl/CS/Cur (PCl:CS=10:2) and $\mathrm{PCl} / \mathrm{CS} / \mathrm{Cur}(\mathrm{PCl}: \mathrm{CS}=10: 4)$.

1. Shankar, S. ; Rhim, J. W., Preparation of sulfur nanoparticle-incorporated antimicrobial chitosan films. Food Hydrocolloids 2018, 82, S0268005X18301681. 